T. VILAYVAN, * C. WINOTAPAN, V. BANPHAVICHIT, T. SHINADA, Y. OHFUNE (CHULALONGKORN UNIVERSITY, THAILAND; OSAKA CITY UNIVERSITY, JAPAN) Indium-Mediated Asymmetric Barbier-Type Allylation of Aldimines in Alcoholic Solvents: Synthesis of Optically Active Homoallylic Amines

J. Org. Chem. 2005, 70, 3464-3471.

\title{
Indium-Mediated Asymmetric Allylation of Aldimines in Methanol
}

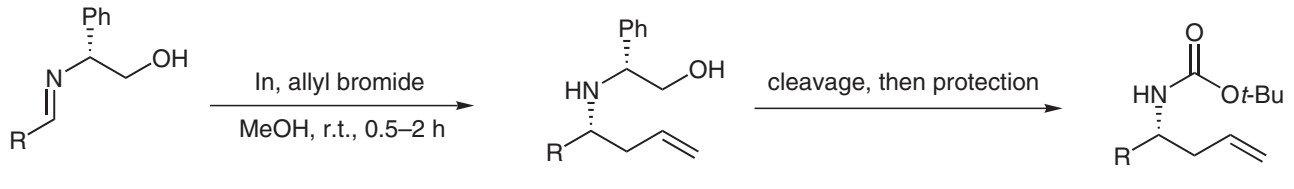

$\mathrm{R}=\mathrm{Ar}$, Hetar, Alk, $c$-Alk
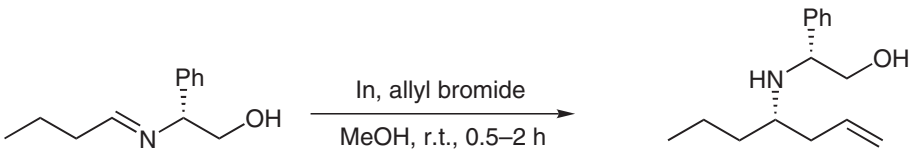

$80 \%$ yield, $>96 \%$ de

Significance: The synthesis of chiral homoallylic amines was easily performed in methanol as a solvent under very mild conditions, thus tolerating a number of functional groups. The reagents and auxiliary used are cheap, and the products can be further transformed into various optically pure products.
Comment: This is probably the simplest route to optically pure homoallylamines from aldehydes. The chiral auxiliary is commercially available and can be removed from the products by a number of ways. Homoallylic amines may serve as intermediates for the synthesis of some important classes of products, therefore such a mild and facile method of their synthesis has been highly desirable. 